\title{
Design Plasticity
}

\author{
Phillip J. Richardson, CD, BA, CSM
}

\begin{abstract}
"First we shape our buildings, thereafter they shape us."-Winston Churchill_May, 1941—upon persuading the British House of Commons to rebuild that just-bombed institution in a manner respectful of the culture from which it had evolved,
\end{abstract}

As Carl Elefante, FAIA American Institute of Architects 2017 First Vice President and 2018 President Elect-said in his Acceptance Statement:

"Churchill's words express a powerful truth that holds the key to architecture's future: architects shape lives." -https://www.carlelefante.com/

How perceptive Churchill was when he observed the interaction and impact of the built space on our culture and society, as well as on individuals...he understood the fundamental impact of the built space on the culture in which each resides... and from which it has sprung.

We, as professional practitioners of delivering the built space know this best of all and most of us recognize the challenge and the responsibility in "getting it right". That said, we all struggle to varying degrees to learn and then respond to the needs and wants of our constituents - average people.

As the mosaic of humanity is changing so rapidly, keeping up to their needs and wants is a full-time job. But to fulfill our roles responsibly, we cannot ignore that they are our fundamental fact... and it's our duty to respect them.

But not only must we strive to meet their current needs but because of the longevity of what we create, we more and more must try to forecast in what direction society will evolve. Since that is extremely difficult, we must ensure that we future proof our creations by designing in as much flexibility as possible.

Happily, we are the beneficiaries of the latest advances in technology that can assist us with this daunting task. While there are plentiful effective tools available, we first have to overcome our own resistance to using them. News Flash: Not all of us embrace change well! But if we frequently remind ourselves that we are the servants of the people rather than their brilliant and creative masters, we can find the flexibility to serve them much better than we have in the past... and we have the means to do it!

Honorary Professor, International Development, Asia for Canadore College in North Bay, Ontario, Canada
While in fact we do shape lives as Mr. Elfante stated, we have an obligation to do so while responding to the needs and wants of our audience. And in order to effect it faithfully, we must first listen to them. Without doing so, we can create an echo chamber in which only the opinions of the practitioners and clients are heard... and we can all be off the true mark.

Let's be honest with ourselves and look at the underlying processes we use that lead from visioning to delivery.... and how often the aspirations and goals of our Masters may be ignored or misapplied!

Next is a chart depiction of the development process I have used successfully with its important phases and gateways flowing from one to the next. It's all very logical and progressively summarizes the steps needed for success. We all have our own versions of this chart which we follow to design and deliver our clients' projects, cost effectively with as much built-in flexibility as possible.

My team and I followed this process to develop The Commercial Collection in Abu Dhabi, UAE, which included Ferrari World, the largest indoor theme park on the planet! We constructed this 200,000 square metre project element in twenty four months from vision to delivery, on time and on budget, for which we received an "exemplary" performance rating from our ultimate leader, the Crown Prince of Abu Dhabi, HRH Sheikh Mohammed Nahyan.

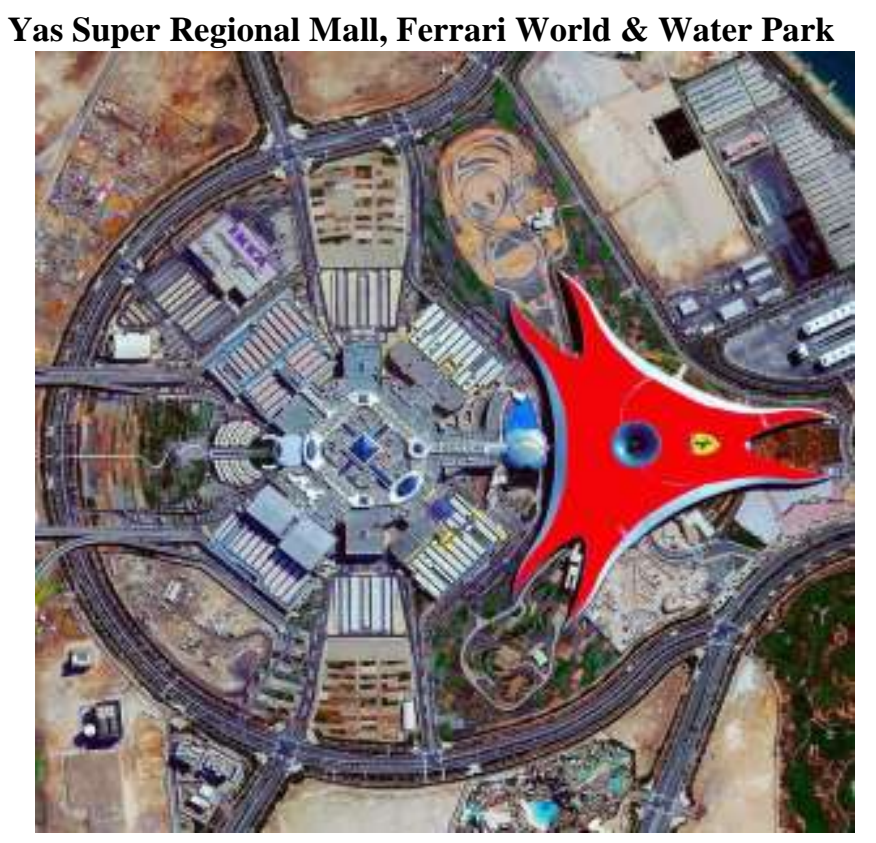


But what did we do that was so different beyond fast tracking the development in a highly organized manner while providing the top-quality results expected by our seniors? The most impactful strategy we employed was based on us reaching out to our prospective customers, in advance, in all major metropolitan areas within six hours flying time! There we conducted interviews and focus groups in order to learn what they wanted us to be for them....and then we future proofed our projects based on what we learned!

While most here would agree that this is a good thing, I personally believe that only a minority actually do something about it. In the rush of winning an assignment and afterwards quickly learning the shape of the immediate site and the owner's mandate, such niceties as familiarizing oneself with the host market may fall by the wayside. I contend then, that such otherwise notable projects run a greater risk of "missing the mark" with their intended customers, not only in the present but even more so in the future.

Not to say there haven't been concerted efforts to do so by many progressive thinkers in the Architectural world. Considerable scholarly thought has been invested in the concept and notable results have been obtained as a result.

For example, Andrew Rabeneck, David Sheppard and Peter Town published two articles related to flexibility and adaptability, with their articles entitled "Housing Flexibility" (1973) and "Housing Flexibility/Adaptability?" (1974).

But I contend that the art of acculturalization has not been often enough applied in order for a claim of true success to be made by us as to producing true design plasticity.

Other contributions have been made by such as Cambridge Architectural Research Ltd. In Design for Flexibility and Adaptation, William Fawcett proposes:

"A crucial advantage of the new approach to flexibility is that the value of lifecycle options can be quantified by simulation, and compared to the cost of providing them. Only if the value is greater than the cost should flexible strategies be pursued. This test encourages investors to adopt flexibility where it is cost-effective, and minimises the risk of overinvesting in expensive flexibility that could never realistically be used.

When a building is designed, the architect makes many decisions, for example between alternative components $A$ and $B$. It is unrealistic to assume that the initial decision will be repeated every time a component is replaced (model I). In a more realistic world view a new decision is made at each replacement (model II). In fact, new components are sure to appear (and old ones disappear), so future decision makers will choose between new alternatives (model III). The future decision opportunities provide flexibility for future decision makers to respond to unfolding events. "

William Fawcett. 'Investing in flexibility: the lifecycle options synthesis.' Projections vol.10, 2011, pp.13-29.

William Fawcett, Martin Hughes, Hannes Krieg, Stefan Albrecht and Anders Vennström. 'Flexible strategies for long- term sustainability under uncertainty' Building Research \& Information vol.40, no.6, 2012.

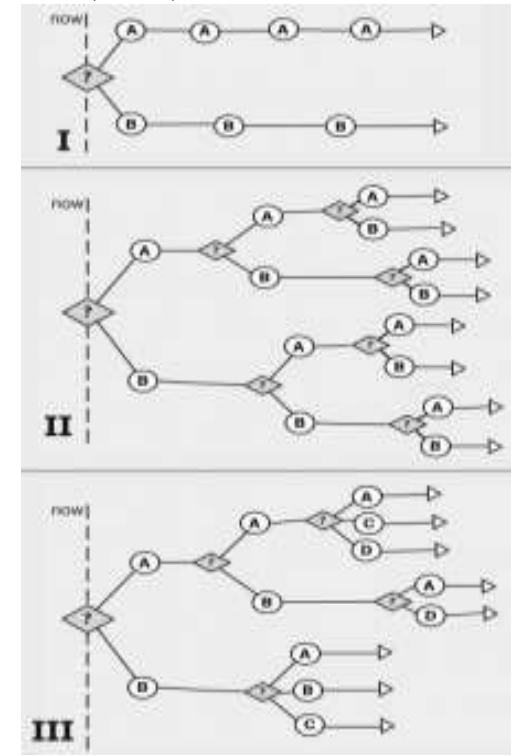

Whilst these deep and powerful thinkers have devised the rational planning and sophisticated control systems sufficiently flexible to help guide future proofing, I still don't believe that we or they, are there yet. What is missing?

The fulfillment of our responsibility to our masters, the People, is only partly satisfied by our technical expertise. It is the empathetic understanding of their wants and needs that has been for many of us, missing.

While many will protest, upon reflection, they will have to admit that we do not use the same sophisticated study of our Masters wants and needs using the equally advanced tools to those I've described, that are also available to us to do so. For us to satisfy the admonition of Churchill we must open our hearts as well as our minds.

For many of us, our technical expertise subconsciously opens up a bias, namely that we think we know best. This hubris is something we can no longer afford to intrude on the fulfillment of our duty to our Masters. 


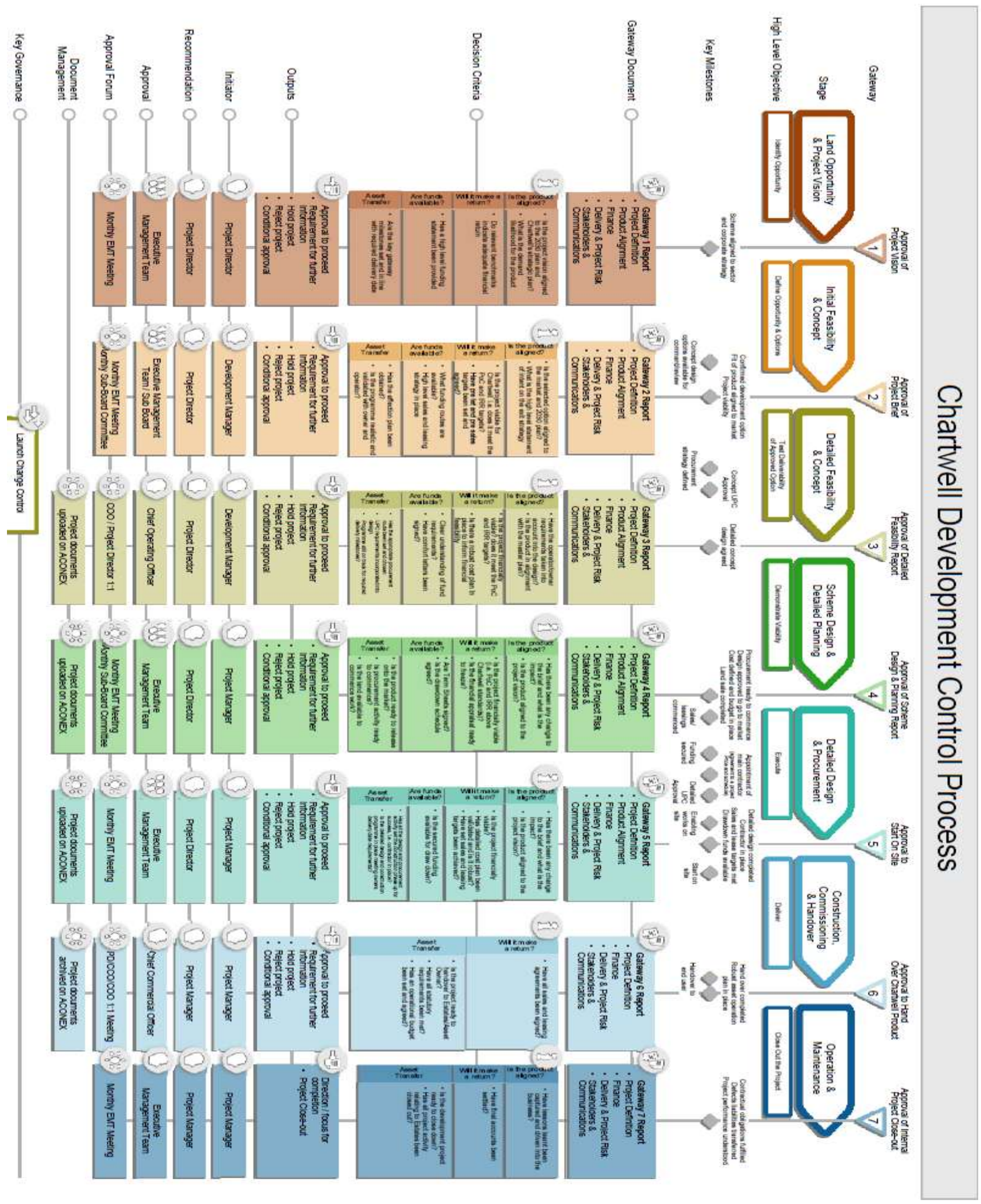


We must all self examine in order to determine our respective inclinations to letting our egos prevail and submit ourselves to an added rigour, that which is afforded to us by Psychology...the study of the inner person. Only a century ago, this scholarly pursuit was widely considered to be a subcategory of Philosophy, and continues to this day to be dismissed by many of our practitioners as the "true" branch of Science that it is.

Allow me to prove it to you. I described my experience in my book "Take The Step Ahead To Double Your Income" $2^{\text {nd }}$ Edition (2015) the creation of the Commercial Collection which I led on Yas Island, Abu Dhabi, UAE.

As I noted before, I led the development of Ferrari World, a 200,000 square metre project that is the largest indoor theme park on the planet. And it enjoys one of the most powerful brands in the world as well, Ferrari.

It is but one element of four in the "Commercial Collection" on Yas Island, consisting, in addition to it, of a super regional mall of 300,000 square metres, a Warner Brothers indoor theme park of 100,000 square metres and a 16 Hectare outdoor waterpark. A very modern and powerful mixed-use development.

Our team of 400 architects, engineers and specialists and I applied the most powerful tools available at the time as did Benoy, the project architect, Shankland-Cox, our project engineers, and all of our many Entertainment specialists from around the world. Using Primavera P6 as our project management system, on our computer dashboards every morning appeared an accurate accounting of all commodities placed and all hours worked to the previous day! We saw the effects on both our schedule and budget and took steps immediately to mitigate any potential adverse effects. We were in control!

But of what? This iconic project was under constant development as we built it. I signed over 800 Design Change Orders as we progressed in order to rationalize our vision with the realities of construction. Some days it felt like we were riding Cavalino, the Prancing Horse of Ferrari! But these were simply the normal actions of a design process flexibly designed to respond to the exigencies of on the spot challenges.

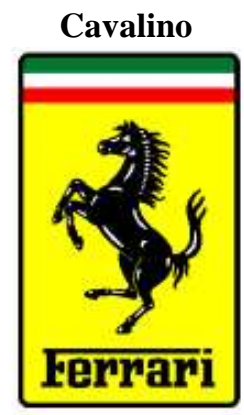

No, the true sign of the design plasticity we employed was more subtle but at the same time, much more powerful. Firstly, we were highly sensitized to the needs of our client/partner, Ferrari. I worked directly with colleagues there up to and including the then Chairman, Luca Di Montezemolo and the then CEO, Jean Todt, and we received their considered input frequently, which was single-mindedly, brand faithful, driven by the needs and wants of their customers and the source of their prosperity.

The very essence of the power and success of their brand was their focus on that customer, one we shared too. In addition to Ferrari's intense and ongoing consumer research, we added our own. We reached out to the citizens of the major cities within several flying hours and asked them what they wanted us to provide to them. And we listened to what they said, making several content and design changes as a result. We tested innovative ideas with our audiences and drew conclusions that were not always convenient to apply but that we found the fibre in ourselves to implement.

But that is not where the process ended. The results of our inquiries were studied and synthesized by specialists in neuroscience to determine the veracity of the participants' responses in order to understand their true meaning. This is most decidedly not a simple Q \& A exercise since there is so much under the surface of the human psyche to take into account in order to extract actionable intelligence.

A case in point:

The essence of the Yas Island Commercial Collection mixed-use development was our integration of entertainment with retail - on steroids! When I studied the initial concept design, I noted immediately that we had robust uses in two of the apexes of the triangular design, roller coasters, but none planned in the apex that faced the Formula One Race track that we were building beside it. I knew how much our audience wanted...craved actually...entertainment, and I reasoned that we should plan a use that responded to that need in this space.
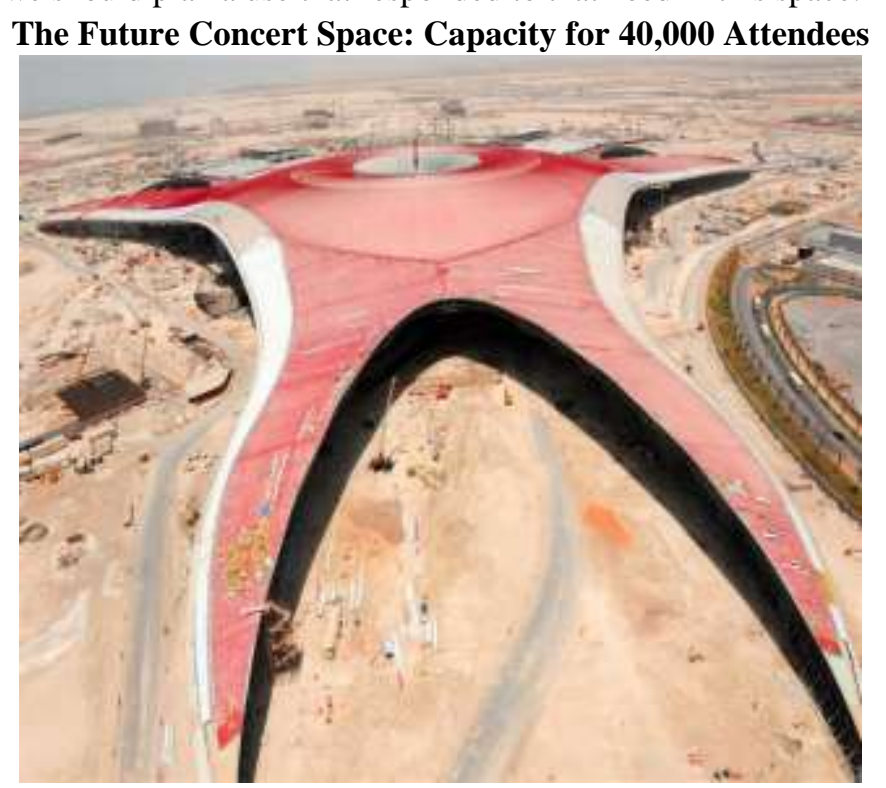

I researched the possibility of including an entertainment venue and after consulting specialists, concluded we should 
include a large concert space in it. I convinced the CEO of the company and was given permission to proceed. Twenty-four months later, with my family, I attended the fourth successive concert held on every night of the four days of the inaugural Abu Dhabi Grand Prix. Aerosmith was playing to a screaming audience of 40,000 people, just as they had been for Beyonce, Jumerquoi, and The Kings Of Leon on the preceding three nights before them...a total of 160,000 very satisfied customers with many more to follow over the years since.

Our willingness to adjust the design and construction plan and to deliver the concert space on time (we couldn't miss the date!) was only a part of the design plasticity we applied. The more important part of the process was what preceded our response. We first had to ask and then to listen to our customers to learn from them and only then to respond to their wants and needs. And before we did, we analyzed the results of interviews and focus groups to verify we were hearing what they were truly saying.

When we were satisfied we had heard them, we then determined the constructability and confirmed the economic feasibility of what we deemed to be the correct response. And we applied this process across all of the rides and attractions we included in Ferrari World with the result that it quickly became the main attraction on Yas Island as the UAE endured the Economic Crisis that followed it's opening. We hosted hundreds of thousands of excited and happy customers over the ensuing difficult years, as it continues to do to this day.

You can now see that the design plasticity of which I speak actually begins with the plasticity of our own thinking as professionals. Our willingness to challenge the "accepted" norms and opt for the more challenging but much more rewarding questioning of our own assumptions and then reaching out to learn what our audience really wants is at the heart of what is needed.

So what can we do to meet this challenge and put our words into action?

Firstly, there are many interested researchers studying consumer behaviour. They are funded by large organizations which prosper from the increased knowledge about how consumers think and behave. They publish regularly and much of their valuable research is available for the asking. Of course, due to the competitive environment in which their clients work, some of it is confidential but because of the increasing velocity of it's application, the shrouds soon fall away. Read their reports and absorb their important lessons so we become sensitized to the importance of this research.

Secondly, we can collaborate with those same neuro scientists in order to inform ourselves about their latest findings and the application they provide to our mandates. We must reach out to these experts because they are our guides into the psyches of our Masters.

Thirdly, we can directly conduct our own research into the subject, with particular goals suited to our specialties. And this must be ongoing, and not a one-time event since trends are so fast moving and influential in our societies.

Fourthly, we need to work with our clients to help them to understand the vital importance of future proofing their projects...on all levels. We must persuade them of the vital nature of this quest, and yes, to accept the "extra" costs of doing so. It is a crucial investment not an expense that they need to make in their own best interests... and that of their Masters.

And lastly, we can convene in forums just such as this one in order to exchange views and update our knowledge. No one person or group has an absolute command of the process and to progress we need to share our findings with one another. I'll leave you with a lesson my father gave me when we worked together in our family property development enterprise. "The best way to learn where to put the sidewalks in a project is to wait for a year after opening and pave where the foot-worn pathways are." I've found that it's even more helpful if we ask our customers directly and in advance of design what they truly want, and then deliver it, because, as Churchill asserted perceptively:

"First we shape our buildings, thereafter they shape us."

There can be no greater calling in our professional service to humanity than to study its ongoing behavioral evolution and change what we design and deliver in accordance with it.

\section{Research Summary and Conclusions}

Carleton Monroe Winslow Jr-"Architectural Education and Behavioral Science" Journal of Architectural Education (1947-1974)

Vol. 18, No. 2 (Sep., 1963), pp. 25-27

Winslow states that "Architects and planners constantly assert that respect for human behavior is central to their design considerations. To some extent this is true...Despite this, more buildings fail anthropologically than structurally and these failure, I suggest are due to 1) inadequate courses in behavioral sciences at the undergraduate level in architectural curricula and 2. lack of empirical research in the isolation of environmental factors as determinants of human behaviour."

In this author's opinion, more time and attention must be paid by the profession in order to remedying this situation so that a higher priority is placed on the social and work activities of the prospective human occupants of the buildings that are the subject of the architects. As well, consideration must be given to future proofing these buildings by engaging futurist sociologists who will have a view on the direction in which society is heading and what features would best suit the then-occupants.

\section{Leidy Klotz- "Using Behavioral Science to Redesign the}

Built Environment" (2017)

Klotz states "I believe similar innovations in the built environment can arise from integrating behavioral science, engineering, and design. Moreover, innovations in the built environment are critical to ensuring a sustainable future. 
Buildings and transportation alone, for example, directly account for nearly half the energy use and carbon dioxide emissions worldwide...

The intersection of behavioral science and user interaction with the built environment has produced engineering advances that address sustainability challenges. Consider smart thermostats that automatically adjust to occupant behavior patterns or heat sensing lights that turn off when no one is in a room. Such systems can save energy and improve the occupant experience and are not limited to thermostats.

However, we must extend behavioral insights for the built environment from users to designers. Transformative innovation happens long before the first room is occupied. Sure, default settings on thermostats can prevent users from wasting energy cooling their homes when no one is there. But what about using defaults that encourage designers to consider passive cooling techniques that eliminate the need for mechanical air conditioning altogether?

Such work applying behavioral science to built environment design is in its infancy, but it does show the potential benefits of a greater focus on this area. For instance, Thomas Beamish and Nicole Biggert's sociology-inspired research on construction organizations finds widespread evidence of what they call a "default design heuristic," a tendency to overuse designs from prior projects."

This author agrees with Klotz particularly when he suggests that habitual repetition in the response of many Architects results in a perpetuation of the old without allowing for the new thinking needed to address the changing needs of people and societies. We must work hard to keep our minds open to respond to changing inputs in order to produce the correct answers for our audience.

What could be more important than that we use all of the strategies and techniques available to us to meet the challenges of improving sustainability? We must stretch our boundaries to do so regardless of the inconvenience or discomfort of change.

Matthew Schwartz, Founder, Director of StrategyConstructive A Branding and Web Design Firm (2012)

Schwartz states "When it comes to branding, design and marketing, behavioral science is big business. While the field's rise from academic obscurity to practical ubiquity has been remarkable, it's not surprising...they can have profound effects when scaled to the macro market.

So what exactly are behavioral sciences, and more important why should you care? The textbook answer is that behavioral sciences use empirical data to investigate how organisms react to stimuli within the context of a social system. In other words, behavioral science means brushing aside our rationalizations about how people think to predict how they will act, and testing how they act to better understand how they truly think.

From the public sector to the private sector, from health to wealth and everywhere in-between, subtle cues-or nudges, to borrow the term-have the potential to transform our world. And the takeaway is this: organizations that take this to heart, who work to understand their audiences a little more deeply, who craft their brand experiences just a little more thoughtfully, should outperform their peers. And while at first the margin may seem insignificant, don't be fooled; victory is achieved one battle at a time."

This area is an integral part of this author's wheelhouse. I took a recent degree in Consumer Psychology knowing how powerfully influential on people is the application of the scientific advances in this field. Imagine if only a part of the promise this field holds generally could be applied to the field of Architecture? Not only will it result in more powerfully serving your audience today but future use of the accelerating advances promised, will yield dramatic results.

\section{BIBLIOGRAPHY}

[1] Carl Elefante, "Acceptance Speech"-FAIA American Institute of Architects (2017)

[2] https://www.carlelefante.com/

[3] Andrew Rabeneck, David Sheppard and Peter Town-"Housing Flexibility" (1973) and "Housing Flexibility/Adaptability" (1974).

[4] http://westminsterresearch.wmin.ac.uk/5894/1/Schneider_Till_2005 as published.pdf

[5] William Fawcett "Design for Flexibility and Adaptation"-- Cambridge Architectural Research Ltd. (2011) http://www.carltd.com/services/buildings/design-flexibility-andadaptation

[6] Phillip J. Richardson "Take The Step Ahead To Double Your Income: 60 Secrets For Success From Around The World" $2^{\text {nd }}$ Edition (2016)

[7] https://www.amazon.com/s/ref=nb_sb_noss?url=searchalias\%3Daps\&fieldkeywords=Take+The+Step + Ahead + To + Double + Your+Income

[8] Carleton Monroe Winslow Jr-Architectural Education and Behavioral Science Journal of Architectural Education (1947-1974)

[9] Vol. 18, No. 2 (Sep., 1963), pp. 25-27

[10] https://www.jstor.org/stable/1423818?seq=1\#page_scan_tab_contents

[11] Leidy Klotz-"Using Behavioral Science to Redesign the Built Environment"-Behavioral Scientist, (2017)

[12] http://behavioralscientist.org/using-behavioral-science-redesign-builtenvironment/

[13] Matthew Schwartz, Founder, Director of Strategy-Constructive A Branding and Web Design Firm (2012)

[14] https://constructive.co/insights/optimizing-audience-engagement-withbehavioral-science/ 